\title{
Original Research \\ Educating patients about warfarin therapy using information technology: A survey on healthcare professionals' perspectives
}

\author{
Sayeed NASSER, Judy MULLAN, Beata BAJOREK
}

ABSTRACT*

Objective: To explore healthcare professionals' views about the benefits and challenges of using information technology (IT) resources for educating patients about their warfarin therapy.

Methods: A cross-sectional survey of both community and hospital-based healthcare professionals (e.g., doctors, pharmacists and nurses) involved using a purpose-designed questionnaire. The questionnaires were distributed using a multi-modal approach to maximise response rates.

Results: Of the total 300 questionnaires distributed, 109 completed surveys were received $(43.3 \%$ response rate). Over half $(53.2 \%)$ of the healthcare participants were aged between $40-59$ years, the majority $(59.5 \%)$ of whom were female. Fifty nine $(54.1 \%)$ participants reported having had no access to warfarin-specific IT-based patient education resources, and a further $19(38.0 \%)$ of the participants who had IT-access reported that they never used such resources. According to the healthcare participants, the main challenges associated with educating their patients about warfarin therapy included: patient-related factors, such as older age, language barriers, cognitive impairments and/or ethnic backgrounds or healthcare professional factors, such as time constraints. The healthcare professionals reported that there were several aspects about warfarin therapy which they found difficult to educate their patients about which is why they identified computers and interactive touch screen kiosks as preferred IT devices to deliver warfarin education resources in general practices, hospital-based clinics and community pharmacies. At the same time, the healthcare professionals also identified a number of facilitators (e.g., to reinforce warfarin education, to offer reliable and easily comprehensible information) and barriers (e.g., time and costs of using IT resources, difficulty in operating the resources) that could impact on the effective implementation of these devices in educating patients about their warfarin therapy.

\footnotetext{
"Sayeed NASSER. Faculty of Pharmacy, University of Sydney. Sydney, NSW (Australia). Judy MULLAN. Graduate School of Medicine, University of Wollongong. Wollongong, NSW (Australia). Beata BAJOREK. Graduate School of Health (School of Pharmacy), University of Technology Sydney. Broadway, NSW; and Departments of Pharmacy and Clinical Pharmacology, Royal North Shore Hospital. St. Leonards, NSW. (Australia).
}

Conclusion: The findings of the study suggest that there is a need for improving healthcare professionals' use of, and access to IT-based warfarin education resources for patients. The study findings also suggest addressing the concerns raised by the healthcare professionals when implementing such IT resources successfully to help educate patients about their warfarin therapy.

Keywords: Health Education. Health Promotion. Information Systems. Warfarin. Australia.

\section{EDUCANDO A PACIENTES SOBRE EL USO TERAPÉUTICO DE WARFARINA UTILIZANDO TECNOLOGÍAS DE INFORMACIÓN: ESTUDIO SOBRE PERSPECTIVAS DE PROFESIONALES DE LA SALUD}

\section{RESUMEN}

Objetivo: Explorar la visión de los profesionales de la salud sobre los beneficios y retos de usar tecnologías de información (TI) para educar pacientes sobre su tratamiento con warfarina. Métodos: Estudio transversal tanto de profesionales de la salud comunitarios y hospitalarios (e.g. médicos, farmacéuticos y enfermeras) que envolvió el uso de un cuestionario específicamente diseñado. Se distribuyeron los cuestionarios utilizando un diseño multi-modal para maximizar las tasas de respuesta.

Resultados: De los 300 cuestionarios distribuidos, se recibieron 109 completos $(43,3 \%$ de tasa de respuesta). Más de la mitad $(53,2 \%)$ de los sanitarios participantes tenían entre 40-59 años y la mayoría $(59,9 \%)$ eran mujeres. 59 participantes $(54,1 \%)$ comunicaron no tener acceso a recursos de TI para educación de pacientes específicos de warfarina, y 19 de los que tenían acceso (38.0\%) comunicaron que nunca los habían utilizado. De acuerdo con los sanitarios participantes, los principales retos asociados con la educación de sus pacientes sobre el tratamiento con warfarina incluían: factores relacionados con los pacientes, tales como elevada edad, barreras lingüísticas, deterioros cognitivos o antecedentes étnicos, o factores de los profesionales de la salud tales como restricción de tiempo. Los profesionales sanitarios comunicaron que había muchos aspectos del tratamiento con warfarina que encontraban difíciles de explicar a sus pacientes, por lo que identificaron los ordenadores y los quioscos interactivos de pantalla táctil como los aparatos de TI preferidos para proporcionar educación sobre warfarina en las 
consultas generales, en las clínicas hospitalarias y en las farmacias comunitarias. Al mismo tiempo, los profesionales de la salud también identificaron varios facilitadores (e.g. reforzar la educación sobre warfarina, ofrecer información fiable y fácilmente comprensible) y barreras (e.g. tiempo y costes de usar las TI, dificultad en manejar esos recursos) que podrían impactar en la implantación efectiva de estos aparatos para educar pacientes sobre su tratamiento con warfarina.

Conclusión: Los hallazgos del estudio sugieren que se necesita mejorar el uso y el acceso de los profesionales de la salud a los recursos educativos para pacientes basados en TI sobre warfarina. El hallazgos del estudio también sugieren afrontar las preocupaciones levantadas por los profesionales al implantar con éxito tales TI para educar pacientes sobre sus tratamientos con warfarina.

Palabras clave: Educación en Salud. Promoción de la Salud. Sistemas de Información. Warfarina. Australia.

\section{INTRODUCTION}

Patient education is an essential component of medication safety, because it improves patients' knowledge of their disease and how to manage their relevant drug therapy. ${ }^{1}$ Historically, healthcare professionals have provided education to patients via face-to-face consultations (i.e., verbal information), often supplementing this with written information and/or simple audiovisual materials. ${ }^{2}$ Recent innovations in the field of Information Technology (IT), however, present an exponentially developing opportunity for health professionals to utilize interactive electronic devices (e.g., computers, the internet, and portable electronic gadgets) within traditional consultations to help educate their patients about health and medicines. ${ }^{2-}$ 4 This new, cost-effective, time-saving and rapidly evolving information technology can also benefit patient education by improving communication between patients, carers and healthcare professionals. $^{3,5,6}$

Given the potential scope of IT-based resources to support patient education ${ }^{7-10}$, they can also be used to educate patients receiving more complicated treatments, such as warfarin therapy. ${ }^{11,12}$ Warfarin is a complex drug and is often associated with lifethreatening adverse drug-related complications, hence patients receiving warfarin therapy require extensive education to optimize therapeutic outcomes. ${ }^{1,13-16}$ Unfortunately, to date, the provision of warfarin education to patients in different clinical settings has generally been inadequate. ${ }^{17-19}$ Therefore, the efficiencies inherent in new information technologies, present an opportunity to facilitate effective and useful warfarin education resources for patients.

As expected in any system that is undergoing a paradigm shift, it is notable, but not surprising, that healthcare professionals have widely variable perceptions regarding the use of new technologybased patient education resources. $70,102-22$ There appears, however, to be limited knowledge about the views and perceptions of healthcare professionals specifically relating to the use of ITbased warfarin education resources. Therefore, this study primarily explores healthcare professionals' (e.g. general practitioners-GPs, pharmacists, nurses) views about the benefits and challenges of using IT resources for educating patients about their warfarin therapy. The specific objectives of this study were to: explore healthcare professionals' access to, and usage of IT resources for educating patients about warfarin; identify perceived facilitators and barriers to using IT resources for educating patients about warfarin; and document characteristics of the healthcare professionals that may impact on their usage of IT resources for educating patients about warfarin.

\section{METHODS}

Design and Settings

A cross-sectional survey of both community and hospital-based healthcare professionals (e.g., doctors, pharmacists and nurses) practicing within NSW was conducted over a 12 week period during May-August, 2011. Relevant ethics approval for this study was received from the Human Research Ethics Committee of the University of Sydney.

\section{Data collection}

A purpose-designed questionnaire, using a mixture of scaled, coded and open-ended responses, was used for data collection. For scaled responses, a 3point scoring system was used, (e.g., 1=least useful/suitable/effective/impact as a response option, and $3=$ most useful/suitable/effective/impact as a response option). For the coded questions, each response option was categorised (e.g., 1=No; $2=$ Yes) and for the open-ended questions, the participants provided free text responses.

The distribution of the questionnaire to participants was multi-modal to maximise response rates, and included postal mail, direct invitation, and group bundles (i.e., bundles of surveys were distributed to group meetings, and a box provided to lodge completed surveys). At all times, the questionnaire was accompanied by a pre-paid return envelope to facilitate its return.

Participants

A purposive sample of community and hospitalbased healthcare professionals, comprising doctors (GPs), community pharmacists, hospital pharmacists, and nurses, was recruited to complete the survey. Using evidence from the literature about the relative proportion of health care professionals involved in educating patients about warfarin therapy ${ }^{11}$, the target sample size of approximately 105 (as appropriate for a pilot, descriptive survey) ${ }^{23}$ was stratified to comprise $60 \mathrm{GPs}, 25$ pharmacists and 20 nurses.

Community-based healthcare practices (i.e. general practices and pharmacies) within the Sydney metropolitan area were identified from the publicly accessible online telephone directory (i.e., the 
Telstra Yellow Pages ${ }^{\mathrm{TM}}$ ) by using relevant search terms (i.e., 'general practitioners', 'pharmacies'), and then selected to receive a postal questionnaire using a similar sampling method described in the literature. ${ }^{24}$ This sampling method involved sending a postal questionnaire to every second general practice/general practitioner address of the 242 total online entries, as well as the first 50 pharmacy/pharmacist addresses of the 53 total online entries. In cases where specific names of the healthcare professionals could not be identified, the questionnaires were addressed to the 'The Doctor' or 'The Pharmacist-in-Charge'. Accounting for the known low response rate of postal surveys ${ }^{25}$, twice as many questionnaires were sent to each of the selected practices, i.e., 120 questionnaires were sent to general practices and 50 were sent to community pharmacies. Reminder questionnaires were then sent to non-responders six weeks after the initial questionnaires had been posted. In addition to the postal questionnaire distribution, a convenience sample of a further 50 communitybased healthcare professionals (i.e., 20 general practitioners and 30 pharmacists) practicing within the Sydney metropolitan area and who were known to the primary researcher, were approached and directly invited to take part in the study.

Hospital-based healthcare professionals (i.e., pharmacists and nurses) working in two NSW metropolitan teaching hospitals were also invited to take part in the study. The questionnaire was distributed via group bundles by placing questionnaires (i.e., 40 per hospital) in group meeting rooms (e.g., common rooms, staff meeting rooms), specifically targeting cardiology wards at the respective hospitals. The completed questionnaires were collected by the primary researcher approximately four weeks later.

\section{Data Analysis}

Descriptive (e.g., proportions, frequencies, medians) and comparative (e.g., cross-tabulations) statistical analyses were performed using the Statistical Package for the Social Sciences (SPSS; version 17.0: 2008) software. A p-value of 0.05 or less was considered statistically significant in this study.

\section{RESULTS}

Of the total 300 questionnaires distributed to community and hospital-based healthcare professionals (i.e., 140 doctors, 120 pharmacists, 40 nurses), 48 were returned unusable (i.e., returned incomplete because of incorrect addresses, unavailability and/or reasons unknown), and 109 completed surveys were received (i.e., response rate of $43.3 \%$ ). Of these 109 completed surveys, 68 were returned via postal mail and the remainders were collected by the primary researcher from the participants. Forty surveys were received from doctors (i.e., 37 GPs, a cardiologist, a vascular surgeon and a respiratory physician); 53 from pharmacists (24 community-based pharmacists and 29 hospital pharmacists) and, 16 from nurses (3 were practice nurses from community-based general practices).

To facilitate age-based data analysis, the age (in years) of the participants was categorised as: $<30$ (16.5\%, $n=18)$; $30-39$ (16.5\%, $n=18) ; 40-49$ (23.9\%, $\mathrm{n}=26) ; 50-59$ (29.4\%, $\mathrm{n}=32) ; 60-69(10.1 \%, \mathrm{n}=11)$; and $>70(3.7 \%, n=4)$. Eighty four $(77.1 \%)$ of the participants identified their gender in the questionnaires, where just over half $(59.5 \%)$ were female. Of the healthcare professional groups, pharmacists represented the majority $(48.6 \%$, $n=53)$, followed by doctors $(36.7 \%, n=40)$ and then nurses $(14.7 \%, \mathrm{n}=16)$.

The majority ( $n=92 ; 84.4 \%$ ) of participants reported that their main strategy for educating their patients about warfarin was a combination of both verbal and written instruction, followed by verbal instructions alone, 14 (12.8\%); written instructions alone, $1(0.9 \%)$; and referral to another educator, 2 $(1.8 \%)$. Of the total participants, 59 (54.1\%) reported having had no access to warfarin-specific IT-based patient education resources (e.g., patientfocused websites, patient education software/games, and audiovisual resources) in their current practice settings.

Figure 1 indicates that more participants aged between 40-59 years reported that they had used IT resources in their practices to educate their patients about warfarin, as compared to the other age groups. Forty one (48.8\%) of the participants including both male and female participants reported the frequency of their IT resources use; however, $15(36.6 \%)$ of them never used such resources in their current practices (Figure 1). No significant differences in the frequency of using IT resources across different age groups and gender of the participants were found $(p=0.48$ and $p=0.54$, respectively).

Of the 50 healthcare professionals who reported that they had access to IT resources, 19 (38.0\%) (including 10 doctors, 8 pharmacists and 1 nurse) had never used such resources for educating their patients about warfarin therapy (Figure 2). No statistically significant difference was found among the healthcare professionals in relation to their frequency of IT resource use, $(p=0.43)$. Among all the participants who had access to IT resources, 31 $(62.0 \%)$ used such resources at least occasionally to help educate their patients about warfarin therapy (Figure 2).

Factors identified by the study participants as adversely impacting on patient education about warfarin were (in descending order of importance): older age of patients; time constraints of the healthcare professionals; as well as the patients' language barriers cognitive impairments and ethnic backgrounds (Table 1). None of the nurse respondents reported that patients' language barriers and ethnicity could adversely affect their warfarin education to patients (Table 1).

The most challenging content areas of warfarin education, ranked in order from highest to lowest, as identified by the participants (Table 2) included: possible dietary interactions; monitoring and 


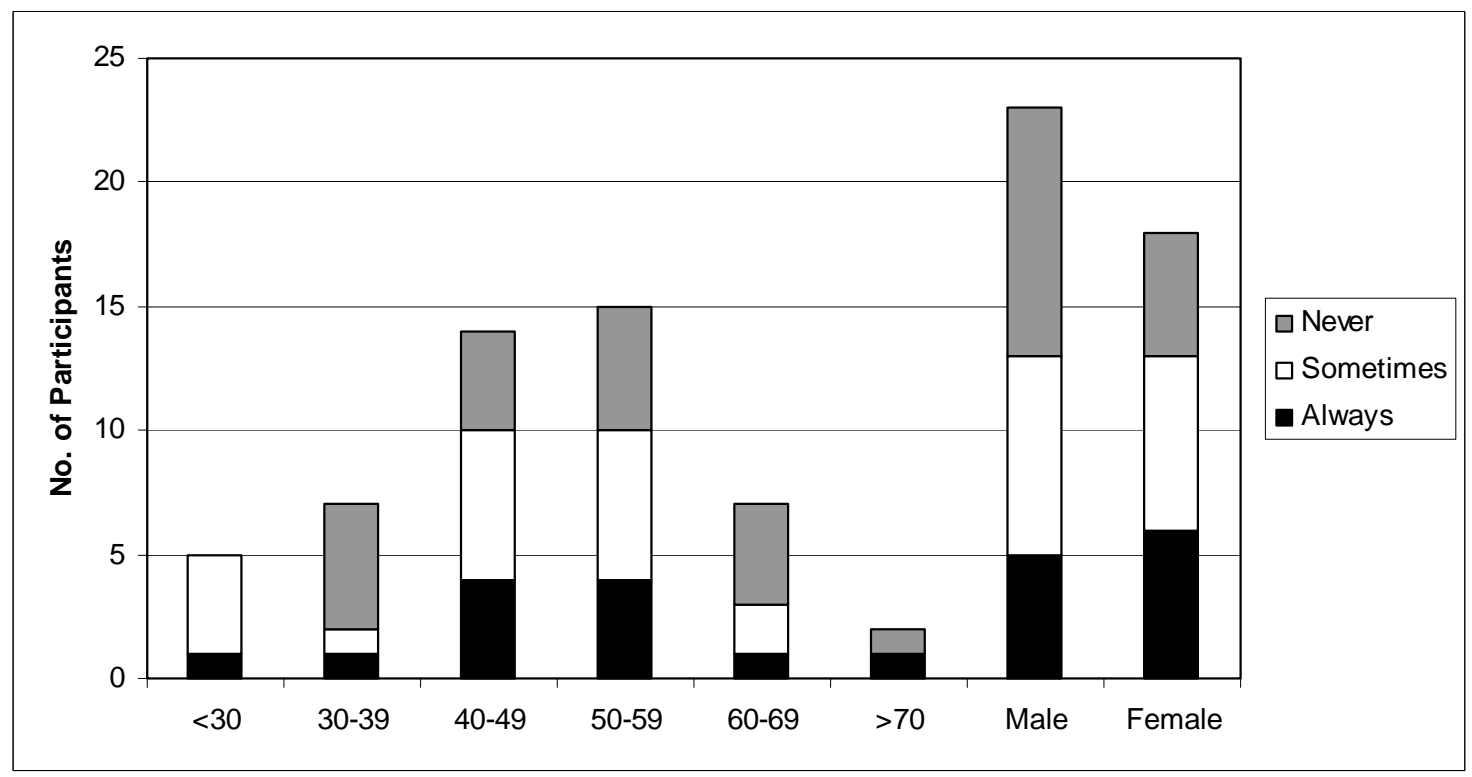

Figure 1: Use of IT resources for patients' warfarin education according to age groups and genders. Note: Only 41 participants out of a total of 84 including both male and female participants reported their frequency of IT use

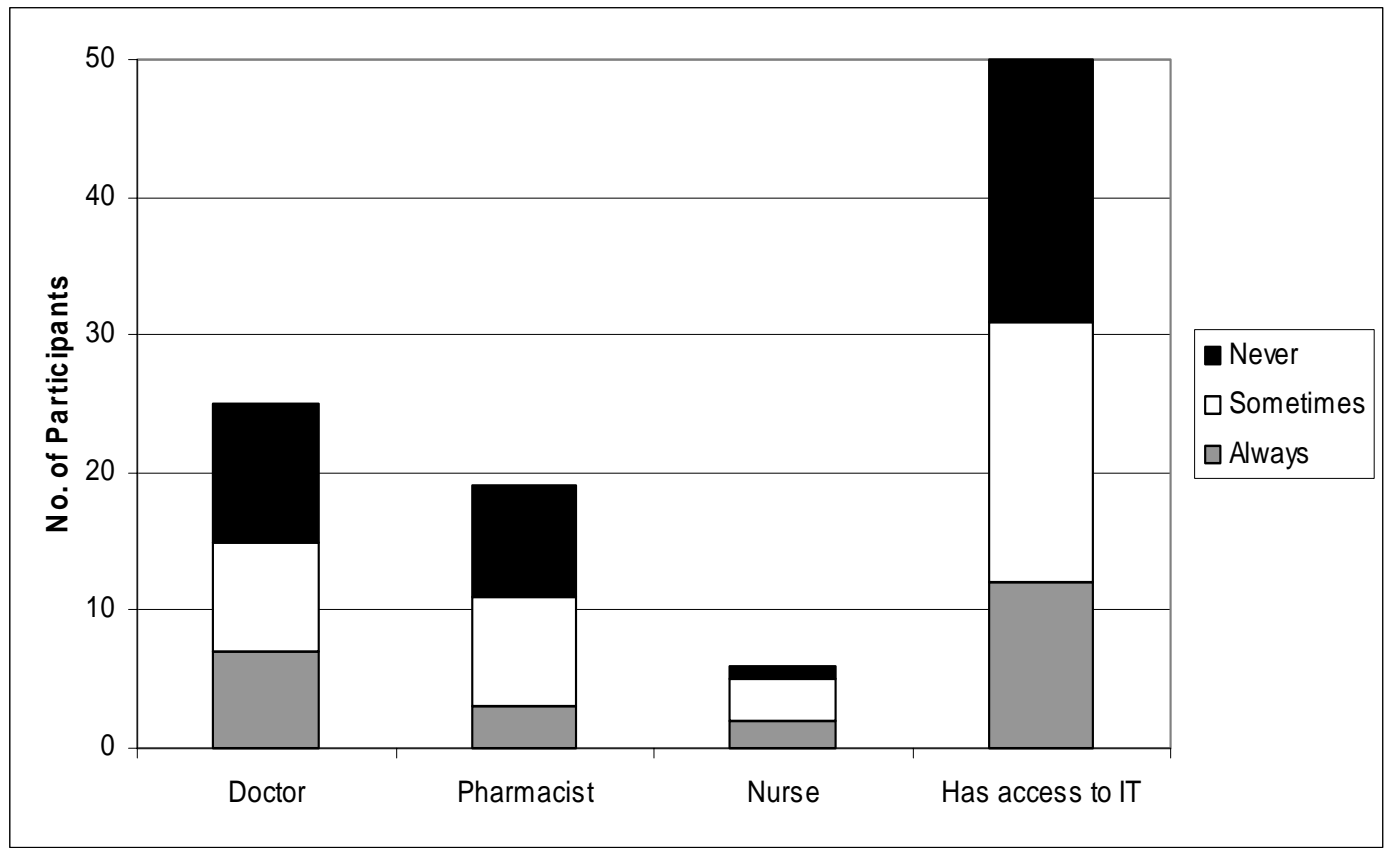

Figure 2. Use of IT resources for patients' warfarin education according to healthcare professional groups and access to IT resources

management of International Normalised Ratio (INR); possible drug to drug interactions; possible risks associated with taking warfarin therapy; and the dosage and administration of warfarin therapy. Similar responses were obtained from each of the health professional participant groups (Table 2).

When identifying suitable IT resources to assist with educating patients about warfarin, the participants suggested that good quality warfarin information, the use of graphics/illustrations/pictograms as well as information in multiple languages were amongst the three most important considerations (Table 3). Although, no significant differences were found between healthcare professionals in regard to the most important considerations, nurses were more likely to report that information available in multiple languages was an important consideration, as compared to doctors and pharmacists (Table 3).

IT devices that were preferred for educating patients were: computers (desktops, laptops and/or tablets) and interactive touch screen kiosks. The 


\begin{tabular}{|l|c|c|c|c|}
\hline \multicolumn{1}{|c|}{ Table 1: Factors affecting patients' warfarin education, as cited by all the healthcare professionals, (N=109) } \\
\hline & \multicolumn{2}{c|}{$\begin{array}{c}\text { Number of healthcare professionals citing } \\
\text { stated factor }\end{array}$} & Notal \\
\cline { 2 - 5 } & Doctor & Pharmacist & Nurse \\
\hline Older age of patients & 12 & 20 & 1 & 33 \\
\hline Time constraints of healthcare providers & 2 & 16 & 12 & 30 \\
\hline Language barriers of patients & 9 & 11 & 0 & 20 \\
\hline Cognitive impairments of patients & 5 & 9 & 3 & 17 \\
\hline Ethnic background of patients & 9 & 4 & 0 & 13 \\
\hline Poor education level of patients & 4 & 7 & 2 & 13 \\
\hline Lack of appropriate education materials & 5 & 2 & 2 & 9 \\
\hline Patients' lack of understanding about the therapy & 1 & 4 & 3 & 8 \\
\hline Information overload for patients & 3 & 1 & 2 & 6 \\
\hline Patients' reluctance to warfarin education & 2 & 2 & 1 & 5 \\
\hline Note: The participants were able to report more than one factor & & \\
\hline
\end{tabular}

participants also indicated that GP practices, hospital-based clinics and community pharmacies were the most suitable locations for offering these IT resources to patients (Table 4).

Based on the responses from the healthcare professionals, a number of facilitators and barriers of implementing IT-based warfarin education resources in the current practice settings were identified which are described below:

Regarding the important role of IT resources in patients' warfarin education, the study participants highlighted the following aspects as the main role (median score of 3.0) of such resources: reinforcing patients' warfarin education; providing reliable information to patients that is easy to read and understand, especially for with limited literacy skills and those from diverse cultural backgrounds. The role of IT resources in reducing healthcare professionals' workload by saving time was a major role according to the nurses (median score of 3.0), but a little less important according to the doctors and pharmacists (median score 2.0). Then finally, all the healthcare participant groups agreed that another less important role of the IT resources was the provision of cost-effective patient education (median score of 2.0).

The study participants indicated the following factors that would impact highly (median score 3.0) on their ability to offer IT resources: costs relating to the purchase or installation of IT resources; set-up of the practice settings for IT-based resources; and time needed to educate patients using the IT resources. Across all three healthcare professional groups, uncertainty about the quality and reliability of IT-based warfarin information was regarded to be a moderate barrier (median score of 2.0) to the use of IT resources in their current practice settings. Unlike the doctors and pharmacists, nurses reported that the factor- relevant training required to operate and/or navigate IT resources had a high impact on their ability to use IT resources in educating patients about warfarin (median score 2.0 versus 3.0, respectively).

Each healthcare professional group indicated that the following factors would have a high impact (median score of 3.0) on the use of IT resources by their patients: difficulty and fear of operating IT resources; patients' preference for face-to-face education from healthcare professionals; and patients' lack of appropriate training to access and/or navigate IT resources effectively. Each group of healthcare professionals reported that a lack of patients' confidence about the quality of IT resources had moderate impact (median score of 2.0) on patients' utilisation of IT resources in their current practice settings.

\section{DISCUSSION}

This study has explored healthcare professionals' (e.g. doctors, pharmacists, nurses) views and perceptions on the benefits and challenges of using IT resources for educating patients about their warfarin therapy. Overall, this study highlights that there is a lack of use of IT-based warfarin education resources, and the reasons for this are multifaceted.

\begin{tabular}{|c|c|c|c|c|c|}
\hline \multirow[t]{2}{*}{ Rank } & \multirow[t]{2}{*}{ Content Area } & \multicolumn{3}{|c|}{$\begin{array}{c}\text { Number of healthcare professionals citing } \\
\text { stated content area } \\
\text { (\% within participant groups) }\end{array}$} & \multirow{2}{*}{$\begin{array}{c}\text { Total } \\
\mathrm{N}=109(\%)\end{array}$} \\
\hline & & $\begin{array}{l}\text { Doctor } \\
\mathrm{n}=40(\%)\end{array}$ & $\begin{array}{l}\text { Pharmacist } \\
\mathrm{n}=53(\%)\end{array}$ & $\begin{array}{c}\text { Nurse } \\
n=16(\%)\end{array}$ & \\
\hline 1 & Possible dietary interactions with warfarin & $32(80.0)$ & $43(81.1)$ & $10(62.5)$ & $85(78.0)$ \\
\hline 2 & INR monitoring and management & $31(77.5)$ & $40(75.5)$ & $8(50.0)$ & $79(72.5)$ \\
\hline 3 & Possible drug-drug interactions with warfarin & $26(65.0)$ & $41(77.4)$ & $10(62.5)$ & $77(70.6)$ \\
\hline 4 & $\begin{array}{l}\text { Possible risks associated with taking warfarin } \\
\text { therapy }\end{array}$ & $23(57.5)$ & $30(56.6)$ & $9(56.3)$ & $62(56.9)$ \\
\hline 5 & Dosage and administration of warfarin therapy & $18(45.0)$ & $21(39.6)$ & $8(50.0)$ & $47(43.1)$ \\
\hline 6 & Managing missed doses of warfarin therapy & $15(37.5)$ & $20(37.7)$ & $10(62.5)$ & $45(41.3)$ \\
\hline 7 & Mode of action of warfarin & $9(22.5)$ & $21(39.6)$ & $9(56.3)$ & $39(35.8)$ \\
\hline 8 & Recognising emergency situations (e.g., bleeding) & $14(35.0)$ & $18(34.0)$ & $4(25.0)$ & $36(33.0)$ \\
\hline 9 & Importance of adherence to warfarin therapy & $15(37.5)$ & $16(30.2)$ & $4(25.0)$ & $35(32.1)$ \\
\hline 10 & Benefits of warfarin therapy & $4(10.0)$ & $7(13.2)$ & $3(18.8)$ & $14(12.8)$ \\
\hline 11 & Indications of warfarin use & $5(12.5)$ & $2(3.8)$ & $2(12.5)$ & $9(8.3)$ \\
\hline
\end{tabular}




\begin{tabular}{|c|c|c|c|c|c|}
\hline \multirow[t]{2}{*}{ Rank } & \multirow{2}{*}{$\begin{array}{l}\text { Important consideration for a suitable IT } \\
\text { resource }\end{array}$} & \multicolumn{3}{|c|}{$\begin{array}{c}\text { Number of healthcare professionals citing stated } \\
\text { considerations about IT resources } \\
\text { (\% within participant groups) }\end{array}$} & \multirow{2}{*}{$\begin{array}{c}\text { Total } \\
\mathrm{N}=109(\%)\end{array}$} \\
\hline & & $\begin{array}{c}\text { Doctor } \\
n=40(\%)\end{array}$ & $\begin{array}{l}\text { Pharmacist } \\
\mathrm{n}=53(\%)\end{array}$ & $\begin{array}{c}\text { Nurse } \\
n=16(\%)\end{array}$ & \\
\hline 1 & Good quality of information & $30(75.0)$ & $35(66.0)$ & $11(68.8)$ & $76(69.7)$ \\
\hline 2 & $\begin{array}{l}\text { Graphics/illustrations or } \\
\text { images/pictograms relevant to warfarin } \\
\text { therapy }\end{array}$ & $21(52.5)$ & $27(50.9)$ & $10(62.5)$ & $58(53.2)$ \\
\hline 3 & Information in multiple languages & $16(40.0)$ & $27(50.9)$ & $10(62.5)$ & $53(48.6)$ \\
\hline 4 & Logical organization of information & $9(22.5)$ & $24(45.3)$ & $7(43.8)$ & $40(36.7)$ \\
\hline 5 & $\begin{array}{l}\text { Audiovisual resources depicting practical } \\
\text { aspects of treatment }\end{array}$ & $14(35.0)$ & $23(43.4)$ & $1(6.3)$ & $38(34.9)$ \\
\hline 6 & Balanced and unbiased information & $15(37.5)$ & $9(17.0)$ & $2(12.5)$ & $26(23.9)$ \\
\hline 7 & $\begin{array}{l}\text { Animation components for better visual } \\
\text { presentation of information }\end{array}$ & $6(15.0)$ & $11(20.8)$ & $1(6.3)$ & $18(16.5)$ \\
\hline
\end{tabular}

One key reason for this underutilisation of IT-based education relates to the poor access of healthcare professionals' to such resources. More than half of the healthcare professionals in this study revealed that they had no access to suitable IT-based warfarin education resources to help educate their patients about warfarin therapy. This finding is consistent with that of previous studies exploring health-related IT resources, reporting that only between $17 \%$ to $50 \%$ of healthcare professionals have access to IT resources to help improve patient education and care. ${ }^{26,27}$ This finding is unfortunate, given that IT-based patient education resources offer advantages over traditional face-to-face patient education strategies in many ways, particularly in that they offer patients relevant information in 'realtime' situations within their own control (e.g., options to repeat and review information as per individual education needs and learning challenges). ${ }^{28,29}$ Further, such resources have been effectively used in other clinical settings to boost patients' knowledge and understanding of their chronic disease conditions and drug therapy. $3,9,29,30$ It is, therefore, recommended that healthcare professionals should be equipped with appropriate IT-based warfarin education resources in their practice settings which could potentially help to improve patient education and consequently their therapeutic outcomes.

Following from the issue of access to IT-based resources is their active utilization; in this study, among those healthcare professionals who did have access to such resources, one-third did not actively use these. Factors identified as contributing to their inadequate use of IT resources in the current practice settings include increased time and costs needed to actively implement these resources in their practice settings as well as their perceived difficulties in using IT resources. However, patient education delivered via IT resources has been proven to be time-efficient and cost-effective in previous studies. ${ }^{5,31,32}$ Lo et al. (2010) reported that the total costs for IT-based patient education services were relatively low compared to that for conventional patient education services. ${ }^{31}$ Further, IT-based patient education has been found to be time-efficient, reporting as much as a $40 \%$ reduction in healthcare professionals' time spent on educating patients. ${ }^{5}$ These time-savings could be particularly significant in the context of warfarin education, given the complexity of the therapy (e.g., frequent INR monitoring, dosage adjustment, drug-drug and dietary interactions) ${ }^{33}$ which mandates the need for comprehensive patient education. Unfortunately, the extensive education required by patients is compromised by the time and resource constraints of healthcare professionals, and this is further aggravated by patient-related factors that might increase patient education needs and efforts, e.g., older age, cognitive and functional impairment, ethnicity, or poor literacy skills). ${ }^{11,18,34}$

In relation to patient-factors impacting on the provision of warfarin education, this study also confirms that these factors, as perceived by healthcare professionals, can adversely impact on the education of patients. However, previous studies have demonstrated the effectiveness of ITbased patient education resources (e.g., CD-ROM, websites, computers) in improving patient knowledge and understanding about their diseases and drug therapy, especially among older patients and those with limited literacy skills, including patients from different ethnic backgrounds. ${ }^{3,35}$ Given the effectiveness of IT resources for patient education, IT-based warfarin education resources that provide good quality and authentic information may be useful supplementary tools for overcoming many of existing challenges of warfarin education.

When considering the potential for the use of ITresources, perhaps one of the main findings of this study is that healthcare professionals (e.g., doctor, pharmacist and nurse) perceive that IT resources could be best used to convey easy-to-read and understandable information to the patient. Additionally, the unique advantages of IT-based resources are that they allow the incorporation of multimedia components, visual graphics, or images, to help effectively convey the information, thus having incredible potential to help improve patients' learning. ${ }^{36,37}$ Given these added benefits, many patients are increasingly turning to IT-based patient education resources (e.g., health websites) to help improve their knowledge and understanding about chronic diseases and drug therapies. ${ }^{38}$ These advantages of IT resources may be regarded as important considerations, when contemplating the 


\begin{tabular}{|c|c|c|c|c|}
\hline Median Scores & $\begin{array}{c}\text { Doctor } \\
n=40\end{array}$ & $\begin{array}{c}\text { Pharmacist } \\
n=53\end{array}$ & $\begin{array}{c}\text { Nurse } \\
n=16\end{array}$ & $\begin{array}{l}\text { Total } \\
\text { Score }\end{array}$ \\
\hline \multicolumn{5}{|c|}{ Potentially useful IT devices ${ }^{\ddagger}$} \\
\hline Desktop computer & 3.0 & 2.0 & 2.0 & 7.0 \\
\hline Tablet computer (e.g., iPad) & 2.0 & 3.0 & 2.0 & 7.0 \\
\hline Portable computer (e.g., Laptop) & 2.0 & 3.0 & 2.0 & 7.0 \\
\hline Interactive touch screen kiosk & 2.0 & 2.0 & 2.0 & 6.0 \\
\hline Wide screen smart phone & 2.0 & 2.0 & 1.0 & 5.0 \\
\hline Portable CD*/DVD** player & 1.0 & 2.0 & 2.0 & 5.0 \\
\hline Personal Digital Assistant (PDA) & 1.5 & 2.0 & 1.0 & 4.5 \\
\hline Handheld audiovisual player & 1.0 & 2.0 & 1.0 & 4.0 \\
\hline \multicolumn{5}{|c|}{ Suitable settings for implementing IT resources ${ }^{\S}$} \\
\hline Hospital-based clinic (e.g., OPD)†† & 2.5 & 3.0 & 3.0 & 8.5 \\
\hline Solo GP surgery & 2.5 & 3.0 & 3.0 & 8.5 \\
\hline Community pharmacy & 2.0 & 3.0 & 3.0 & 8.5 \\
\hline GP medical centre & 3.0 & 3.0 & 2.0 & 8.0 \\
\hline Hospital pharmacy & 2.0 & 2.0 & 3.0 & 7.0 \\
\hline Patient's home & 2.0 & 2.0 & 3.0 & 7.0 \\
\hline Hospital ward & 2.0 & 2.0 & 3.0 & 6.5 \\
\hline Aged care facility & 2.0 & 2.0 & 2.0 & 6.0 \\
\hline \multicolumn{5}{|c|}{$\begin{array}{l}{ }_{1} 1=\text { Not useful; } 2=\text { Moderately useful; } 3=\text { Very useful } \\
{ }_{1} 1=\text { Not suitable; } 2=\text { Moderately suitable; } 3=\text { Very suitable } \\
{ }^{*} \text { CD=Compact Disc; }{ }^{* * D V D=D i g i t a l ~ V e r s a t i l e ~ D i s c ; ~ † † O P D=O u t p a t i e n t ~ D e p a r t m e n t ~}\end{array}$} \\
\hline
\end{tabular}

benefits of using IT resources to supplement patient education about medications with low therapeutic indices such as warfarin.

A key strength of this study is that it is the first, to our knowledge, to investigate multidisciplinary healthcare professionals' perspectives about the benefits of, and barriers to, using IT resources to assist with educating patients about warfarin therapy, as well as identifying their current usage of such resources. In regard to study limitations, the number of participants and the diverse methods of recruitment means that the study findings might not be generalisable to healthcare professionals and practice settings more broadly. Nevertheless, the information generated from this study provides a foundation to help address and facilitate the implementation of IT-based warfarin education resources for patients.

\section{CONCLUSIONS}

The findings of this study indicate that few of the healthcare professionals used or even had access to IT-based warfarin education resources in their current treatment settings. Further, this study found that both community and hospital based healthcare professionals had generally positive views about the use of IT resources, although with some reservations regarding the implementation and use of such resources in their practice settings. Based on these findings, this study suggests the need for improving healthcare professionals' use of, and access to IT-based warfarin education resources in their practices. Further, any future attempt in implementing such IT resources should address the concerns raised by many of the healthcare professionals relating to the effective use of IT resources. More research is needed to address the effectiveness of IT resources on patient knowledge and understanding of anticoagulation therapy, and more importantly, on INR control.

\section{CONFLICT OF INTEREST}

None declared.

\section{References}

1. Bajorek BV. A review of the safety of anticoagulants in older people using the medicines management pathway: weighing the benefits against the risks. Ther Adv Drug Saf. 2011;2(2):45-58.

2. Stoop AP, van't Riet A, Berg M. Using information technology for patient education: realizing surplus value? Patient Educ Couns. 2004;54(2):187-195.

3. Wofford JL, Smith ED, Miller DP. The multimedia computer for office-based patient education: a systematic review. Patient Educ Couns. 2005;59(2):148-157.

4. Hegney D, Eley R, Buikstra E, Fallon T, Soar J, Gilmore. Australian Nurses Access and Attitudes to Information Technology- A National Survey H-A Park et al (Eds);IOS Press in: Consumer-Centered Computer-Supported Care for Healthy People; 2006. p688-692.

5. Lewis D. Computer-based Approaches to Patient Education: A Review of the Literature. J Am Med Inform Assoc. 1999;6(4):272-282.

6. Luo N, Koh WP, Ng WY, Yau JW, Lim LK, Sim SS, Tay EG. Acceptance of Information and Communication Technologies for Healthcare Delivery: A SingHealth Polyclinics Study. Ann Acad Med Singapore. 2009;38(6):529-528.

7. Jackson CL, Bolen S, Brancati FL, Batts-Turner ML, Gary TL. A Systematic Review of Interactive Computer-assisted Technology in Diabetes Care Interactive Information Technology in Diabetes Care. J Gen Intern Med. 2006;21(2):105110. 
8. Strömberg A, Ahlén H, Fridlund B, Dahlström U. Interactive education on CD-ROM- a new tool in the education of heart failure patients. Patient Educ Couns. 2002;46(1):75-81.

9. Flynn $D$, van Schaik $P$, van Wersch $A, A$ med $T$, Chadwick $D$. The utility of a multimedia education program for prostate cancer patients: a formative evaluation. $\mathrm{Br} \mathrm{J}$ Cancer. 2004;91(5):855-860.

10. Celler BG, Lovell NH, Basilakis J. Using information technology to improve the management of chronic disease. Med J Aust. 2003;179(5):242-246.

11. Nasser S, Mullan J, Bajorek B. Challenges of older patients' knowledge about warfarin therapy. J Prim Care Community Health. 2012;3:65-74.

12. Denizard-Thompson N, Singh S, Wells M, Wofford JL. Using iPod technology for warfarin education: Mobile computerassisted patient education for improving office efficiency [abstract]. J Gen Intern Med. 2008;23(Suppl 2):230.

13. Beyth RJ, Quinn L, Landefeld CS. A multicomponent intervention to prevent major bleeding complications in older patients receiving warfarin. Ann Intern Med. 2000;133(9):687-695.

14. Pirmohamed M, James S, Meakin S, Green C, Scott AK, Walley TJ, Farrar K, Park BK, Breckenridge AM. Adverse drug reactions as cause of admission to hospital: prospective analysis of 18820 patients. BMJ. 2004;329(7456):15-19.

15. Khan TI, Kamali F, Kesteven P, Avery P, Wynne H. The value of education and self-monitoring in the management of warfarin therapy in older patients with unstable control of anticoagulation. Br J Haematol. 2004;126(4):557-564.

16. Pernod G, Labarère $P$, Yver J, Satger B, Allenet B, Berremili T, et al. EDUC'AVK: reduction of oral anticoagulant-related adverse events after patient education: a prospective multicenter open randomized study. J Gen Intern Med. 2008;23(9):1141-1146.

17. Tang EO, Lai CS, Lee KK, Wong RS, Cheng G, Chan TY. Relationship between patients' warfarin knowledge and anticoagulation control. Ann Pharmacother. 2003;37(1):34-39.

18. Kagansky N, Knobler H, Rimon E, Ozer Z, Levy S. Safety of Anticoagulation Therapy in Well-informed Older Patients. Arch Intern Med. 2004;164(18):2044-2050.

19. Cheah GM, Martens KH. Coumadin Knowledge Deficits: Do Recently Hospitalized Patients Know How to Safely Manage the Medication? Home Healthc Nurse. 2003;21(2):94-100.

20. Lee FW. Adoption of electronic medical records as a technology innovation for ambulatory care at the medical university of South Carolina. Top Health Inf Manage. 2000;21(1):1-20.

21. Schmitt M, Titler M, Herr K, Ardery G. Challenges of web-based education in educating nurses about evidence-based acute pain management practices for older adults. J Contin Educ Nurs. 2004;35(3):121-127.

22. Ullrich PF, Vaccaro AR. Patient Education on the Internet: Opportunities and Pitfalls. Spine (Phila). 2002;27(7):E185188.

23. Henning J. Recommended Sample Size for Accurate Surveys. http://blog.vovici.com/blog/bid/18119/RecommendedSample-Size-for-Accurate-Surveys (accessed 22 August 2011).

24. Paul CL, Walsh RA, Tzelepis F. A monetary incentive increases postal survey response rates for pharmacists. J Epidemiol Community Health. 2005;59(12):1099-1101.

25. Crouch S, Robinson P, Pitts M. A comparison of general practitioner response rates to electronic and postal surveys in the setting of the National STI Prevention Program. Aust N Z J Public Health. 2011;35(2):187-189.

26. Miller RH, Hillman JM, Given RS. Physician Use of IT: Results from the Deloitte Research Survey. J Healthc Inf Manag. 2004;18(1):72-80.

27. Brooks RG, Menachemi N. Physicians' Use of Email With Patients: Factors Influencing Electronic Communication and Adherence to Best Practices. J Med Internet Res. 2006;8(1):e2.

28. Keulers BJ, Spauwen PH. Can face-to-face patient education be replaced by computer-based patient education? Eur J Plast Surg. 2003;26:280-284.

29. Huang JP, Chen HH, Yeh ML. A Comparison of Diabetes Learning With and Without Interactive Multimedia to Improve Knowledge, Control, and Self-Care Among People With Diabetes in Taiwan. Public Health Nurs. 2009;26(4):317-328.

30. Neafsey PJ, Strickler Z, Shellman J, Chartier V. An interactive technology approach to educate older adults about drug interactions arising from over-the-counter self-medication practices. Public Health Nurs. 2002;19(4):255-262.

31. Lo SF, Wang YT, Wu LY, Hsu MY, Chang SC, Hayter M. A cost-effectiveness analysis of a multimedia learning education program for stoma patients. J Clin Nurs. 2010;19(13-14):1844-1854.

32. Proudfoot JG. Computer-based treatment for anxiety and depression: is it feasible? Is it effective? Neurosci Biobehav Rev. 2004;28(3):353-363.

33. Bajorek BV, Ogle SJ, Duguid MJ, Shenfield GM, Krass I. Balancing risk versus benefit: the elderly patient's perspective on warfarin therapy. Pharm Pract (Internet). 2009;7(2):113-123.

34. Khan TI, Kamali F, Kesteven P, Avery P, Wynne $\mathrm{H}$. The value of education and self-monitoring in the management of warfarin therapy in older patients with unstable control of anticoagulation. Br J Haematol. 2004;126(4):557-564.

35. Sobel RM, Paasche-Orlow MK, Waite KR, Rittner SR, Wilson EA, Wolf MS. Asthma 1-2-3: A Low Literacy Multimedia Tool to Educate African American Adults About Asthma. J Community Health. 2009;34(4):321-327.

36. Hawley ST, Zikmund-Fisher B, Ubel P, Jancovic A, Lucas T, Fagerlin A. The impact of the format of graphical presentation on health-related knowledge and treatment choices. Patient Educ Couns. 2008;73(3):448-455.

37. Mansoor LE, Dowse R. Effect of Pictograms on Readability of Patient Information Materials. Ann Pharmacother. 2003;37(7-8):1003-1009.

38. Andreassen HK, Bujnowska-Fedak MM, Chronaki CE, Dumitru RC, Pudule I, Santana S, Voss H, Wynn R. European citizens' use of E-health services: A study of seven countries. BMC Public Health. 2007;7:53. 